\title{
Trajetória institucional de um instituto público de pesquisa: 0 caso do Ital após 1995*
}

\author{
Ana Elisa Brito Garcia** \\ Sergio Luiz Monteiro Salles Filho***
}

SumÁrio: 1. Introdução; 2. Material e método; 3. Análise dos resultados; 4. Considerações finais.

Summary: 1. Introduction; 2. Material and method; 3. Result analysis; 4. Final remarks.

Palavras-chave: inovação organizacional; instituto público de pesquisa; modelo institucional; modelo gerencial; trajetória institucional; Ital.

KEY WORDs: organizational innovation; public research institute; institutional model; managerial model; institutional trajectory; Ital.

Este artigo analisa a evolução organizacional de um instituto público de pesquisa tecnológica, o Instituto de Tecnologia de Alimentos (Ital) por meio de um estudo de caso, num período de 10 anos. Aplica pela primeira vez os conceitos de modelos institucional e gerencial. Por modelo institucional entende-se a evolução das características jurídicas que permitem a uma instituição o cumprimento de suas funções sociais. O modelo gerencial compreende dois componentes: o compulsório

\footnotetext{
* Artigo recebido em ago. 2008 e aceito em mar. 2009.

** Doutora em economia pelo Instituto de Economia da Universidade de Campinas (Unicamp). Mestre em ciências sociais pela Universidade de São Paulo (USP). Cientista social pela USP. Pesquisadora científica VI do Centro de Pesquisa e Desenvolvimento de Chocolates, Balas, Confeitos e Panificação - Cereal Chocotec do Instituto de Tecnologia de Alimentos da Agência Paulista de Tecnologia dos Agronegócios (Ital/Apta). Endereço: Av. Brasil, 2.880 - Jardim Brasil — CEP 13070-178, Campinas, SP, Brasil. E-mail: anelisa@ital.sp.gov.br.

*** Livre docente pela Universidade de Campinas (Unicamp). Doutor em economia pela Unicamp. Mestre em ciências agrárias pela Universidade Estadual Paulista (Unesp). Engenheiro agrônomo pela Universidade Federal Rural do Rio de Janeiro (UFRRJ). Professor titular do Departamento de Política Científica e Tecnológica do Instituto de Geociências da Unicamp (IG/Unicamp). Endereço: Universidade Estadual de Campinas, Rua João Pandiá Calógeras, 51, Cidade Universitária Zeferino Vaz — Distrito de Barão de Geraldo — CEP 13083-870, Campinas, SP, Brasil. E-mail: monteirosalles@gmail.com.
} 
e o estratégico. O primeiro trata da gestão dos processos decorrentes do modelo institucional, e o segundo, daqueles que são frutos de suas decisões estratégicas. A principal característica do Ital é ser uma instituição híbrida, pois juridicamente é um instituto público de pesquisa, mas gerenciado, em alguns aspectos, como uma empresa privada altamente inovadora. Na sua trajetória institucional, o Ital adotou uma organização descentralizada, o que lhe permitiu aprofundar os laços com o setor produtivo e aumentar a participação das fontes extraorçamentárias no seu orçamento total. O componente estratégico de seu modelo gerencial teve um peso muito grande nesse desenvolvimento. No entanto, seu modelo organizacional começa a apresentar sinais de esgotamento, colocando desafios para a sua continuidade como instituição de referência.

\section{Institutional trajectory of a public research institute: the case of} Ital after 1995

This article analyzes the organizational development of a public research institute, the Food Technology Institute (Ital), during a period of 10 years. It applies the case study methodology and, for the first time, the concepts of institutional and managerial models. The first concept emphasizes the evolution of the formal characteristics which allow any institution to carry out its social functions. On the other hand, the managerial model consists of two components, the mandatory one, which results from the institutional model, and the strategic one, which results from the methods developed to organize and to conduct the institutuion's strategic decisions. The conclusion is that Ital's main characteristic is to be a hybrid institution, because, although being a legal public institute of research, it has been managed as a highly innovative private enterprise in many aspects. In its institutional trajectory Ital has adopted a decentralized organization which has allowed it to deepen relations with the private sector and to increase the participation of non-government resources in its budget. The strategic component of its managerial model has greatly influenced Ital's organizational development. However, its organizational model is beginning to show signs of fatigue, challengingr its continuity as a reference institution.

\section{Introdução}

Como instituto público de pesquisa (IPP), o Instituto de Tecnologia de Alimentos (Ital) integra o Sistema Nacional de Inovação e construiu, em seus mais de 40 anos de vida, um patrimônio de conhecimentos científico e tecnológico altamente relevante para a tecnologia de alimentos e, consequentemente, para a indústria de alimentos. Em 1995, por iniciativa própria, o Ital passou por uma reestruturação organizacional profunda, cujos motivadores essenciais foram: a rigidez de sua estrutura funcional e as restrições financeiras que a instituição vinha sofrendo por décadas seguidas. O primeiro era resultante de sua con- 
dição de órgão da administração direta, mas as dificuldades financeiras eram fruto da lenta redefinição do papel do Estado que, de proativo, coordenador e financiador da pesquisa básica e aplicada para a agricultura e a indústria de alimentos, passou aos poucos a perder sua capacidade de financiamento e a impingir aos IPPs severas reduções de recursos para pessoal, custeio e investimento (Garcia e Salles-Filho, 2005).

Após a reestruturação, a preocupação do Ital foi criar um padrão de gestão que envolvesse maior aproximação com o setor produtivo, tanto no que diz respeito à captação de recursos financeiros como à garantia de sua inserção competitiva num novo ambiente de pesquisa e transferência de tecnologia, que envolvia novos atores, públicos e privados, concorrendo diretamente com as atividades dos IPPs, e que exigia não apenas excelência científica e tecnológica, mas também eficiência organizacional e gerencial. O resultado foi que os clientes da iniciativa privada passaram a ter grande importância para a instituição.

Essa importância tem significado a priorização dos serviços em detrimento da pesquisa? A aproximação com o setor produtivo pode levar o instituto a ser totalmente financiado pelo setor privado? Quais são as perspectivas futuras para o Ital? São questões importantes que se colocam, quando se procura conhecer o processo de revitalização institucional empreendido pelo Ital, a partir de 1995.

Este artigo analisa as transformações ocorridas nos modelos institucional e gerencial do Ital, decorrentes da implementação do processo de reorganização da instituição, avaliando suas implicações para o cumprimento de suas funções de organização pública de ciência e tecnologia e suas perspectivas para o futuro.

\section{Material e método}

O referencial analítico utilizado foi o desenvolvido por Salles-Filho e colaboradores (2000; 2000a e 2005). Para os autores, os IPPs são entidades que criam conhecimento específico e competências e, como tal, aprendem e evoluem científica, tecnológica e organizacionalmente. Consequentemente, são entidades que têm trajetórias evolutivas, resultantes de um processo ativo de busca, decisões institucionais e relacionamentos com o meio ambiente científico, tecnológico, econômico e social. Esse conceito salienta o processo de aprendizagem como o elemento central na qualificação dos IPPs. 
O processo de aprendizagem e a evolução levam ao conceito de trajetórias institucionais, pois os IPPs, como outras instituições, estão sujeitos às incertezas, aos efeitos de lock-in ${ }^{1}$ e às condições irreversíveis, e são guiados por rotinas de buscas inerentes ao processo técnico-científico. O dinamismo do conceito está em que os IPPs não são predeterminados, mas influenciam e são influenciados pelo ambiente em que se inserem, têm trajetórias evolucionárias e são socialmente selecionados, ou seja, podem se manter importantes e ativos ou podem se extinguir. Disso resulta a necessidade de aprender e evoluir para definir e mudar suas rotinas e para criar, manter e renovar suas competências. A capacidade de permanentemente avaliar suas rotinas permite a renovação de suas competências e habilidades essenciais, que é a lógica do processo de reorganização institucional. Esse processo de busca não é nem linear, nem ao acaso, pois uma vez tomada uma decisão, o conjunto de opções disponíveis no momento é imediatamente modificado, o que o torna um processo de aprendizado inesgotável. Todo processo de busca é seguido de um processo de seleção pelo mercado ou pelo ambiente institucional, com forte efeito de realimentação, o que implica que o processo de aprendizado é também um processo evolucionário.

Portanto, a proposta teórica de interpretação das instituições de pesquisa enfatiza a necessidade que essas instituições têm de mudar, reorganizar-se e evoluir para evitar o lock-in e a inércia institucional e, assim, ter competitividade.

Competitividade institucional é um conceito que vai além da excelência científica, pois é entendida também como aptidão e agilidade para enfrentar e participar das mudanças. Implica a aplicação do conceito de concorrência às instituições públicas de pesquisa, pois, num cenário de mudança global, tem surgido um novo ambiente para a pesquisa pública, com a entrada de novos atores (universidades, centros privados de pesquisa, firmas de consultoria, fornecedores de equipamentos e de insumos que oferecem consultorias, entre outros) e com as mudanças nos padrões de competição do processo de avanço do conhecimento e de geração de inovação. Nesse novo cenário, os institutos públicos de pesquisa competem por recursos seja de fomento, seja da iniciativa privada.

Completando esse referencial analítico, o presente trabalho utiliza os conceitos $^{2}$ de modelo institucional e gerencial, sustentando que a evolução e a

\footnotetext{
${ }^{1}$ As inovações tecnológicas ou organizacionais estão na dependência de trajetórias que nem sempre caminham na direção do sucesso, pois eventos fortuitos podem produzir bloqueios que inviabilizem a continuidade do desenvolvimento da tecnologia ou da organização ou ajam a favor de tecnologias ou organizações inferiores (Kim e Nelson, 2005).

${ }^{2}$ Desenvolvido teoricamente por Sergio-Salles e aplicado empiricamente, pela primeira vez, neste artigo.
} 
dinâmica de uma instituição pública de pesquisa podem ser melhor apreendidas através deles e que, num ambiente competitivo, a aptidão e a agilidade de uma instituição para enfrentar e participar das mudanças estão condicionadas pelos dois modelos.

O modelo institucional é constituído pelas características formais dentro das quais ela é legalmente concebida, ou seja, os contornos jurídicos que permitem o cumprimento de suas funções sociais. Há diversos tipos de modelos institucionais definidos pela legislação brasileira, tanto de direito público quanto privado. No caso de uma instituição pública, o modelo institucional compõe as formas básicas de sua inserção na estrutura do Estado, bem como os direitos e restrições daí decorrentes.

Por modelo gerencial entendem-se as formas pelas quais a instituição organiza e conduz seus processos básicos de gestão, isto é, a organização das atividades-fim e meio e a condução dos seus fluxos e processos decisórios. Há uma interação entre este e o modelo institucional, pois parte do modelo gerencial é consequência do modelo institucional, podendo ser denominado componente mandatório; e parte é de escolha da instituição, ou seja, fruto de suas decisões estratégicas, denominado componente estratégico, conforme mostra a figura 1 .

Interação entre modelo institucional e modelo gerencial

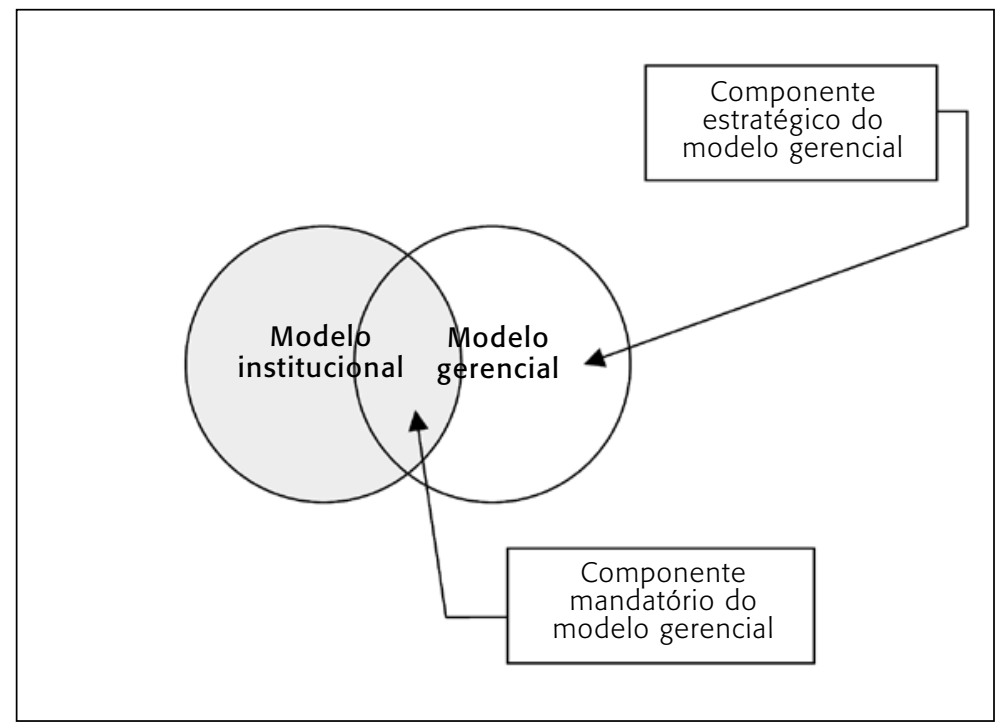


Assim, o modelo gerencial deve ser analisado em seus dois componentes, mandatório e estratégico, uma vez que ambos permitem tomar decisões sobre como a instituição deve se organizar para melhor cumprir sua missão e atingir seus objetivos estratégicos.

O método aplicado para analisar a evolução dos modelos institucional e gerencial, no Ital, foi o estudo de caso. Esse método é muito utilizado nas ciências sociais por ser "um método de olhar para a realidade social" (Goode e Hatt, 1960:422). É uma técnica específica de analisar uma unidade social, um meio de organizar os dados sociais dessa unidade, preservando o seu caráter unitário, ou seja, considerando seu todo. Vale dizer: é um método que permite incluir o estudo do desenvolvimento dessa unidade, analisando-a de um ponto de vista holístico, isto é, preservando a totalidade do objeto social. A totalidade de qualquer objeto de análise, seja ele físico, biológico ou social, "é uma construção intelectual definida em termos que são mais úteis para o problema da pesquisa" (Goode e Hatt, 1960:425).

Nesse método, é importante coletar uma grande variedade de dados para se obter informações substanciais sobre as várias facetas da vida da unidade que está sendo investigada, mas a sua amplitude deve ser guiada pelo problema pesquisado. $\mathrm{O}$ método de estudo de caso também se distingue por utilizar registros de dados econômicos, históricos, políticos, entre outros, com o intuito de acrescentar dimensões à unidade social estudada. Análises estatísticas, desenvolvimento de índices e tipos são também usados na caracterização da unidade. Mas a ênfase deve ser dada ao processo e ao tempo, ou seja, "às mudanças no tempo, bem como ao processo através do qual aquelas modificações se realizam" (Goode e Hatt, 1960:427). Não importa que o período de tempo seja curto ou longo, mas sim que se registrem as características relevantes da interação. "A ênfase no processo de interação torna mais simples manter o caráter unitário do objeto social" (Goode e Hatt, 1960:428).

O período estudado foi de 1995 a 2005 e as fontes de dados utilizadas foram o banco de dados do Ital, seus relatórios anuais de atividade, os relatórios de gestão dos vários ciclos do Projeto Excelência na Pesquisa Tecnológica, dos quais o Ital participou, os documentos da qualidade, os relatórios das pesquisas de cliente externo e cliente interno, planos diretores, artigos e livros escritos sobre o Ital. 


\section{Análise dos resultados}

\section{Evolução do modelo institucional}

O Ital é um órgão de pesquisa da administração direta do estado de São Paulo desde seu nascimento, em 30 de agosto de $1963 .{ }^{3}$ Ter sido da administração direta nos seus primórdios, época em que o estado estava diretamente interessado no desenvolvimento da pesquisa científica e tecnológica no país, foi uma grande vantagem competitiva para a instituição. Os primeiros 15 anos de sua existência foram de rápido crescimento, muito dinamismo e realizações, onde a conjugação de esforços nacionais e internacionais fez com que o órgão se consolidasse como uma importante instituição de pesquisa na área de ciência e tecnologia de alimentos (Garcia e Salles-Filho, 2005). No entanto, dificuldades resultantes de sua condição de órgão da administração direta foram bastante sentidas em vários períodos de sua existência, especialmente no que toca aos seus recursos financeiros e humanos. ${ }^{4}$ Essas dificuldades constituíram-se na semente de um processo de aprendizagem organizacional que desembocou numa busca ativa por modelos institucionais (fundação, autarquia, entre outros) que pudessem dar mais autonomia e agilidade à instituição, permitindolhe um crescimento sustentável. O resultado dessa busca culminou, em 1995, com sua reestruturação. ${ }^{5}$

Por iniciativa própria, a instituição implementou um novo modelo organizacional, novo para a instituição e para os institutos públicos de pesquisa do país, isto é, uma inovação organizacional radical. De acordo com o Manual de Oslo, a inovação organizacional efetivada pelo Ital pode ser classificada como do tipo organizational innovation in business practices (OECD/European Communities, 2005:51), ou seja, a implementação de novos métodos para organizar as rotinas e os procedimentos de trabalho com o objetivo de aprofundar os laços com o setor produtivo.

O que de novo e radical teve a reorganização do Ital pode ser assim resumido: a inserção do Ital na estrutura do estado manteve-se a mesma, ou seja, órgão de pesquisa da administração direta, com nível de departamento

\footnotetext{
${ }^{3}$ Diário Oficial do Estado de São Paulo, Decreto no 42.424, de 30 de agosto de 1963.

${ }^{4}$ De 1971 a 1978, a diminuição do pessoal de apoio foi de 27,5\%; a redução dos recursos extraorçamentários se iniciou em 1975, quando então representavam $49 \%$ dos recursos disponíveis, chegando em 1978 a representar $12 \%$ do total (Garcia e Salles-Filho, 2005).

${ }^{5}$ Diário Oficial do Estado de São Paulo, Decreto no 40.301, de 6 de setembro de 1995.
} 
técnico, subordinado à Coordenadoria de Pesquisa Agropecuária - CPA (denominada depois Agência Paulista de Tecnologia do Agronegócio - Apta), ${ }^{6}$ juntamente com os demais cinco institutos de pesquisa da Secretaria de Agricultura e Abastecimento do Estado de São Paulo. ${ }^{7}$ Ampliaram-se, no entanto, sua missão e o escopo de suas finalidades; seu organograma foi mudado radicalmente e um novo modelo de administração interna e relação entre suas unidades e a direção-geral foi adotado.

À atividade-fim pesquisa e desenvolvimento (P\&D) acrescentaram-se outras, ampliando o escopo de suas finalidades: na pesquisa e aplicação de métodos e técnicas de preparo, processamento, armazenamento e conservação de alimentos, expandiu-se a sua atuação para promoção de métodos de avaliação de qualidade das matérias-primas, alimentos processados e embalagens. A assistência tecnológica e a transferência de tecnologia ao setor produtivo ficaram claramente explicitadas em suas finalidades, consolidando-se uma atuação que começara a tomar corpo nos anos 1970 e se reforçara com a criação da Fundação de Desenvolvimento da Pesquisa Agropecuária (Fundepag), em 1978. Foi dada maior ênfase ao treinamento de profissionais da iniciativa privada e à colaboração na formação de novos profissionais. Foi mudado o perfil de sua participação na assistência aos órgãos oficiais, passando a incluir estudos, projetos, normatização e padronização relacionados aos alimentos e às embalagens (Teixeira e Tisselli, 1991; Diário Oficial do Estado de São Paulo, Decreto no 52.167, de 14 de julho de 1969; e Diário Oficial do Estado de São Paulo, Decreto no 40.301, de 6 de setembro de 1995).

São definidas como atividades-fim de uma organização aquelas desenvolvidas com a finalidade de cumprir a sua missão (OCDE, 2003). As atividades-fim do Ital, após 1995, ficaram claramente definidas como: pesquisa (básica, aplicada e desenvolvimento experimental); assistência tecnológica e transferência de tecnologia ao setor produtivo; e treinamento e formação de profissionais e de estudantes.

Para melhor cumprir sua nova missão, o Ital foi reorganizado em centros e laboratórios; os primeiros segmentados por tipo de indústria de alimentos e produtos afins, conforme a matéria-prima de origem, e os segundos, por

\footnotetext{
${ }^{6}$ Pelo Decreto no 43.037, de 15 de abril de 1998, a Coordenadoria de Pesquisa Agropecuária foi extinta. Em 11 de maio de 2000, pelo Decreto no 44.885, foi criada a Agência Paulista de Tecnologia do Agronegócio, à qual os institutos de pesquisa da Secretaria de Agricultura e Abastecimento estão subordinados.

${ }^{7}$ Instituto Agronômico, Instituto Biológico, Instituto de Zootecnia, Instituto de Pesca e Instituto de Economia Agrícola.
} 
tipo de análise (Ital, 2007). Seguindo o exemplo internacional de empresas do setor produtivo e de organizações de pesquisa, a instituição reduziu os níveis hierárquicos e diminuiu drasticamente o número de unidades técnicas, tendo passado de um organograma que incluía três divisões, 22 seções técnicas, três seções não técnicas e inúmeros setores constituídos pelas usinas-piloto e por aqueles subordinados às seções não técnicas, para um organograma que compreendia sete centros de pesquisa tecnológica, com nível de divisão técnica, nas áreas de carnes (CTC), hortifrutícolas (Fruthotec), laticínios (Tecnolat), chocolates, balas e confeitos (Chocotec), cereais e panificação (Cepec), embalagens (Cetea), e química de alimentos e nutrição aplicada (Química); um Centro de Informações em Alimentos (Cial); e dois laboratórios de controle de qualidade; o de microbiologia de alimentos (Microbiologia) e o de análises físicas, sensoriais e estatísticas (Lafise), ambos com nível de seção técnica. À Diretoria-Geral do instituto estavam diretamente ligados a Secretaria de Acompanhamento de Projetos e Serviços, o Conselho Diretor e o Conselho Consultivo. O Conselho Diretor era composto pelo diretor-geral, pelos diretores dos centros de pesquisas tecnológicas e pelo diretor administrativo. De fato, o diretor administrativo não participava das reuniões e faziam parte delas os representantes dos laboratórios de controle de qualidade. Todos os participantes, à exceção do diretor-geral, eram, internamente, denominados coordenadores. O Conselho Consultivo, formado pelo diretor-geral e mais 12 representantes de entidades do setor público e privado, deveria se reunir a cada seis meses.

Nessa reestruturação, entretanto, não foi possível efetuar as mudanças pretendidas na área administrativa, que só foi redesenhada em 1998, quando o Ital passou por nova reorganização, dessa vez por iniciativa da CPA e em conjunto com todos os institutos de pesquisa da Secretaria de Agricultura e Abastecimento. ${ }^{8}$

Nessa nova reorganização, a CPA foi extinta e todos os institutos de pesquisa passaram a se subordinar diretamente ao secretário de Agricultura e Abastecimento do estado de São Paulo. Junto ao gabinete do secretário foi criado o Conselho Superior da Pesquisa Agropecuária (CSPA). O Ital teve suas áreas técnicas e administrativas reorganizadas, passando a ter a seguinte estrutura: o diretor-geral, o Conselho Superior do Ital, que substituiu o Conselho Consultivo, a assistência técnica e o Comitê de Pós-Graduação. No mesmo

${ }^{8}$ Diário Oficial do Estado de São Paulo, Decreto no 43.037, de 15 de abril de 1998. 
nível dos centros tecnológicos, foram criados o Centro de Coordenação de Pesquisa, o Centro de Tecnologia Avançada em Alimentos e o Núcleo de Comercialização de Produtos e Serviços. O Comitê de Pós-Graduação nunca foi implantado e os dois últimos centros e o Núcleo de Comercialização nunca funcionaram de fato. Os centros tecnológicos se reduziram a seis com a fusão do Chocotec com o Cepec, que passou a ser denominado Centro de Tecnologia de Chocolates, Balas, Confeitos e Panificação - Cereal Chocotec. Os laboratórios de qualidade tiveram a denominação mudada para núcleos.

Em 2000, a Apta foi criada e todos os institutos da SAA ficaram subordinados a ela. Em 2002, a Apta e todos seus institutos foram reorganizados. ${ }^{9}$ O Ital passou a ter a seguinte estrutura: à Diretoria-Geral ficaram diretamente ligados o Conselho Técnico-Científico, ${ }^{10}$ a assistência técnica, a assistência de ação regional, os centros de pesquisa e desenvolvimento e os antigos núcleos. Os centros ficaram divididos em seis áreas: de carnes; de chocolates, balas, confeitos e panificação; de embalagem; de hortifrutícolas; de laticínios; e de química de alimentos e nutrição aplicada. Os núcleos de microbiologia de alimentos e de análises físicas, sensoriais e estatísticas tiveram seu nome mudado para Unidades Laboratoriais de Referência. Extinguiram-se o Conselho Superior do Ital, o Centro de Tecnologia Avançada em Alimentos, o Centro de Coordenação de Pesquisa e o Núcleo de Comercialização de Produtos e Serviços.

Merece referência a dinâmica das mudanças no organograma do Ital. Desenhado, em 1995, para ser uma organização de pesquisa e assistência tecnológica enxuta, tanto em número de cargos, quanto em número de unidades técnicas, e que concentrasse a massa crítica e a responsabilidade pelas plantas-piloto, laboratórios, equipamentos, pessoal etc. nessas mesmas unidades, os dirigentes e os pesquisadores que apoiavam a reestruturação do Ital, que eram na época a grande maioria, não contavam com três fatores críticos: a sua subordinação ao órgão que coordena todos os institutos de pesquisa da Secretaria de Agricultura e Abastecimento, os problemas de gestão e as resistências que teriam de enfrentar dentro de suas unidades. Em todos os casos de mudanças organizacionais, o fator de sucesso repousa em pessoas que, por sua vez, dependem de ter ou não visão de longo prazo, visão estratégica, capacidade de perceber a dinâmica das instituições públicas de pesquisa inseridas

\footnotetext{
${ }^{9}$ Decreto oㅜ 46.488, de 8 de janeiro de 2002 .

${ }^{10}$ Composto pelo diretor-geral, pelos diretores dos centros, de um representante da assistência técnica e um representante da assitência de ação regional.
} 
num contexto de rápidas mudanças científicas, tecnológicas e organizacionais, de coordenar com autoridade, mas sem autoritarismo, de aglutinar, de delegar e muitas outras qualidades que, em última análise, são pessoais. Do lado do órgão que o coordena, o Ital enfrentou duas reorganizações de sua estrutura que não levaram em consideração suas necessidades e o modo como tinha se reestruturado em 1995 e, assim, foi obrigado a ter o mesmo desenho institucional que os demais cinco institutos da SAA, totalmente diferentes entre si, tanto em termos de seu objeto de pesquisa quanto dos clientes a que atendem. Do lado interno, ou seja, de suas unidades, o Ital fechou áreas consideradas superadas e improdutivas, fundiu centros e viu surgir o Grupo Especial de Engenharia (GEE), depois Grupo de Engenharia e Pós-Colheita (GEPC), fruto da aglutinação de pesquisadores dissidentes de outras unidades, e teve que enfrentar fortes resistências internas e problemas de gestão e relacionamentos pessoais dentro das unidades.

Um aspecto importante da dinâmica das mudanças no organograma geral foi a implantação, em 1998, do Sistema de Gestão da Qualidade no Ital, que adquiriu tamanha importância que teve sua inclusão no organograma, diretamente ligado à Diretoria-Geral, mas como uma estrutura ainda não formalizada oficialmente, como muitas que surgiram durante o período estudado, como mostram as figuras 2 e 3 .

\section{Evolução do modelo gerencial}

O componente mandatório do modelo gerencial adotado por época da reestruturação, isto é, as formas básicas de organização de suas atividades-fim e meio e do processo decisório estavam dadas nos decretos que reorganizaram a instituição. Seu componente estratégico, no entanto, permitiu a evolução do modelo gerencial por meio de um processo contínuo de aperfeiçoamento e inovações organizacionais incrementais.

\section{Componente mandatório}

Como órgão da administração direta, o Ital continuou subordinado à CPA, e depois à Apta. Mas, internamente, as relações formais de subordinação entre o diretor-geral, os diretores de centros e laboratórios e os funcionários das unidades ficaram mais diretas, com a eliminação dos intermediários, anteriormente existentes. 


\section{Figura 2 \\ Organograma oficial do Ital em 1995}

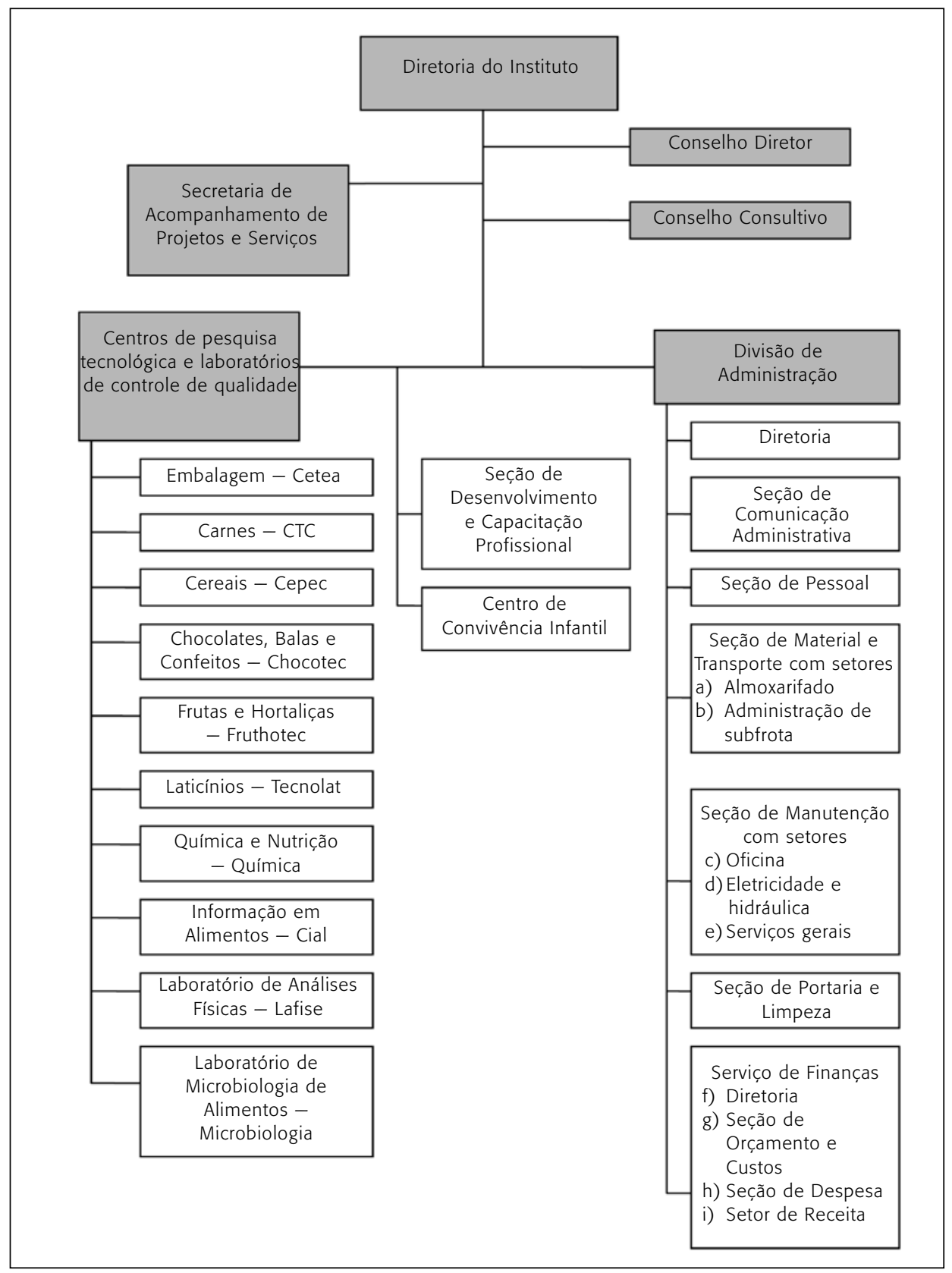


Figura 3

\section{Organograma funcional do Ital em 2005}

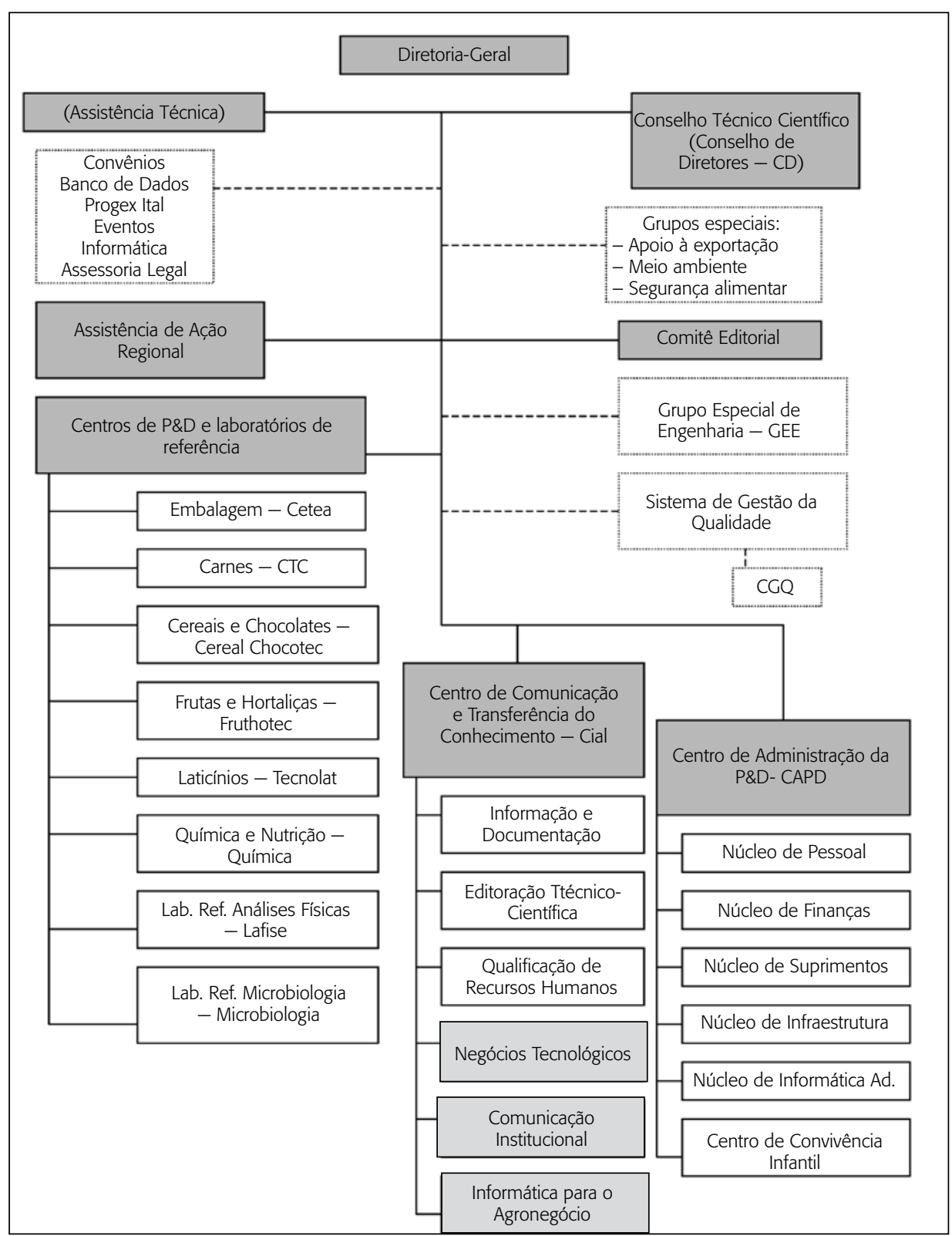

Fonte: Ital (2007).

$\square=$ estrutura ainda não formalizada oficialmente;
$\square=$ estruturas ainda não implantadas. 
Na definição e execução de seu orçamento dentro do governo do estado de São Paulo (Gesp), o Ital continuou a ter pouca flexibilidade, pois não existe um mecanismo que lhe assegure o montante de recursos previsto para ele no início do ano, já que esses continuam a ser consignados na forma de dotação orçamentária, sobre a qual são aplicadas as cotas de regularização, que podem cortar ou suplementar seu orçamento, dependendo da disponibilidade de recursos arrecadados pelo estado.

Na gestão dos recursos humanos estatutários, o componente mandatório do modelo gerencial se impõe em todos os níveis da força de trabalho pois, através da carreira de pesquisador científico, carreira de assistente técnico de pesquisa científica e tecnológica e carreira de apoio à pesquisa, o estado define a estrutura de cargos, remuneração, critérios e processo de avaliação e acesso. A contratação de funcionários estatutários é feita por meio de concurso público de títulos e provas e está dependente de autorização de novos concursos e restrições da Lei de Responsabilidade Fiscal, assim como o aumento de vagas.

Merece destaque a carreira do pesquisador científico, que é gerenciada por uma comissão externa, a Comissão Permanente de Regime de Tempo Integral (CPRTI), órgão técnico colegiado do governo do estado, que abrange 18 instituições de pesquisa do estado, distribuídas entre as Secretarias de Estado da Agricultura e Abastecimento, do Meio Ambiente, da Economia e Planejamento e da Saúde, e um quadro de pesquisadores que, desde sua criação em 1975, tem variado entre 1.200 e 1.600 pessoas (Tolezano et al., 2006).

A carreira trouxe inúmeras vantagens para o desenvolvimento da pesquisa científica e tecnológica no estado, entre elas o estancamento da evasão de técnicos altamente especializados e treinados, atraídos por melhores salários quer pela iniciativa privada, quer pela carreira acadêmica, o que muitas vezes inviabilizava pesquisas e programas. Suas características básicas são: administração pelo sistema de autogestão; sistema continuado de avaliação; avaliação entre pares, por profissionais escolhidos pela comissão entre os altamente capazes em suas áreas de atuação; parâmetros e critérios de avaliação definidos em leis complementares e decretos, previamente divulgados a cada ano; avaliação da produção científica e tecnológica não apenas pela quantidade, mas também pelo grau de qualidade e originalidade; sistema concorrencial de acesso, em que cada pesquisador concorre com a população de pesquisadores de seu nível e não apenas com aqueles de sua instituição; entre outros aspectos (Tolezano et al., 2006).

Essas características imprimiram à carreira de pesquisador científico uma grande credibilidade e um dinamismo no processo de desenvolvimento 
científico e tecnológico dos pesquisadores. No entanto, a carreira de pesquisador científico está fora da alçada do dirigente de qualquer IPP, ou seja, não há possibilidade de um dirigente tomar ações no sentido de mudar o peso ou acrescentar critérios de avaliação na carreira para atender às políticas de planejamento e financiamento das atividades-fim de sua instituição ou às políticas de pessoal ou mesmo àquelas que possam afetar o rumo de sua instituição. No Ital, onde se incentiva o trabalho direto com a iniciativa privada, a carreira acaba criando conflitos internos para pesquisadores que são excelentes no atendimento às demandas do setor privado, mas têm pouco ou quase nenhum tempo para o desenvolvimento de suas pesquisas e elaboração de artigos científicos.

\section{Componente estratégico}

O modelo gerencial implantado com a reestruturação de 1995 foi internamente denominado "descentralizado com condições centrais". ${ }^{11}$ Com autonomia, ${ }^{12}$ o modelo gerencial descentralizado evoluiu no sentido de sua efetiva implantação, tendo o Ital implementado várias inovações organizacionais. No processo de evolução, algumas inovações caminharam em direção a um lock-in, tendo sido abandonadas ou se mantido apenas em algumas unidades técnicas, enquanto outras se mantiveram e se aperfeiçoaram num processo de melhoria contínua.

\section{DESCENTRALIZAÇÃO COM CONDIÇÕES CENTRAIS}

A nova metodologia de trabalho institucional se baseou em um processo de cross fertilization ideas, ou seja, em conhecimentos absorvidos das consultorias pré-reestruturação, acesso a estudos internacionais sobre reorganização de institutos de pesquisas, públicos e privados, e em experiências de sucesso implantadas em uma unidade do Ital, o Cetea. Acreditava-se que a coalizão de profissionais capacitados e voltados para o estudo e resolução de problemas

\footnotetext{
${ }^{11}$ Denominação utilizada pela primeira vez pelo diretor-geral na abertura da primeira reunião do Conselho Consultivo, no ano de 1997.

12 "Entende-se por autonomia a capacidade interna (de fato e de direito) de decisão, sem necessidade de consulta às instâncias hierárquica superiores" (Geopi — Roteiro para diagnóstico, trabalho de reorganização institucional do CTA).
} 
de um mesmo setor da indústria de alimentos aumentaria a massa crítica e a capacidade de aprendizado de seus quadros (learning capabilities) e, em decorrência, sua capacidade criativa, de resolução dos problemas e de absorção dos conhecimentos (absorptive capabilities); que aumentaria a capacidade de atendimento das demandas do setor e a união de esforços dos pesquisadores e técnicos na busca de recursos para suas unidades aumentaria o volume de recursos captados.

Assim, o critério por excelência para a condução do instituto foi o de agrupamento dos pesquisadores em centros tecnológicos e laboratórios de apoio e de descentralização das decisões, mas obedecendo a condições centrais. O objetivo primordial, por trás desse arranjo institucional, era o de aumentar sua capacidade de gerar recursos não orçamentários, uma vez que a dependência exclusiva de recursos do Tesouro não permitiria a sustentabilidade da instituição como IPP de excelência científica e tecnológica, como era a visão que a motivara para a reestruturação. Suas UTs passaram a ser encaradas pela Direção-Geral como unidades de negócio. Mesmo os núcleos ou unidades laboratoriais de referência foram tratados como unidades de negócio. Passaram a ser exigidos das UTs o conhecimento dos mercados em que atuam, o estabelecimento dos produtos a serem oferecidos à iniciativa privada, o desenvolvimento de pesquisa científica e tecnológica, o gerenciamento dos recursos externos captados junto à iniciativa privada e às agências de fomento, o gerenciamento dos recursos humanos, ${ }^{13}$ estatutários e contratados, o estabelecimento de seus próprios critérios e formas de avaliação e incentivo de seus funcionários e a adoção do próprio modo de gerenciar as UTs.

Entre as condições centrais, foi estabelecido como norma trabalhar com a Fundação do Desenvolvimento da Pesquisa do Agronegócio (Fundepag), ${ }^{14}$ fundação auxiliar que já vinha atendendo ao instituto desde 1978. A formulação de convênios e contratos com a iniciativa privada e órgãos públicos deveria ser realizada via Fundepag. Estabeleceu-se, também, que cada UT, ao

\footnotetext{
${ }^{13}$ Cada unidade técnica desenvolveu o seu próprio método e política de incentivo de seus recursos humanos. O Cetea foi o primeiro centro do Ital a utilizar a avaliação de desempenho de seus funcionários alinhada com seus objetivos estratégicos, metas e planos de ação, tendo por base a metodologia do "balanced scorecard". Em 2004, o Centro de Química iniciou o processo de implantação da "avaliação estratégica", como é chamada a avaliação de desempenho no centro. ${ }^{14}$ Fundada em 1978, com a denominação Fundação do Desenvolvimento da Pesquisa Agropecuária e com o objetivo de desenvolver a ciência e a tecnologia aplicadas às atividades agropecuárias e agroindustriais, a Fundepag é uma entidade privada sem fins lucrativos, que atende a 14 instituições de pesquisa ligadas ao agronegócio.
} 
receber os recursos provenientes da iniciativa privada através da fundação auxiliar, depois de pagar a taxa administrativa (10\%), deve repassar $20 \%$ para a Diretoria-Geral do Ital (DG), que administra esses recursos para despesas de manutenção e investimentos que atendam ao instituto como um todo.

No período 1995-2005, o aumento dos recursos oriundos da iniciativa privada foi de $233,9 \%$, com sua participação nos recursos totais passado de $29,1 \%$ a 38,7\%, e ápice em 2003, quando representou 39,7\%. O índice arrecadação/ pesquisador passou de $\mathrm{R} \$ 22,8 \mathrm{mil} / \mathrm{PqC}$, em 1995 , para $\mathrm{R} \$ 84,8 \mathrm{mil} / \mathrm{PqC}$, em 2005 , incremento de $271,9 \%$. A participação dos recursos de fomento não teve o comportamento desejado, mas assim mesmo seu incremento foi praticamente constante de 1995 a 2002, quando chegou a $\mathrm{R} \$ 3,1$ milhões, depois caindo e estabilizando-se no patamar de R \$ 2,5 milhões (figura 4). De 1995 a 2005, os recursos de agências de fomento passaram de $\mathrm{R} \$ 5,7 \mathrm{mil} / \mathrm{PqC}$ para 25,9 mil/PqC.

Figura 4

Receita do Ital por fonte de recursos, 1995-2005

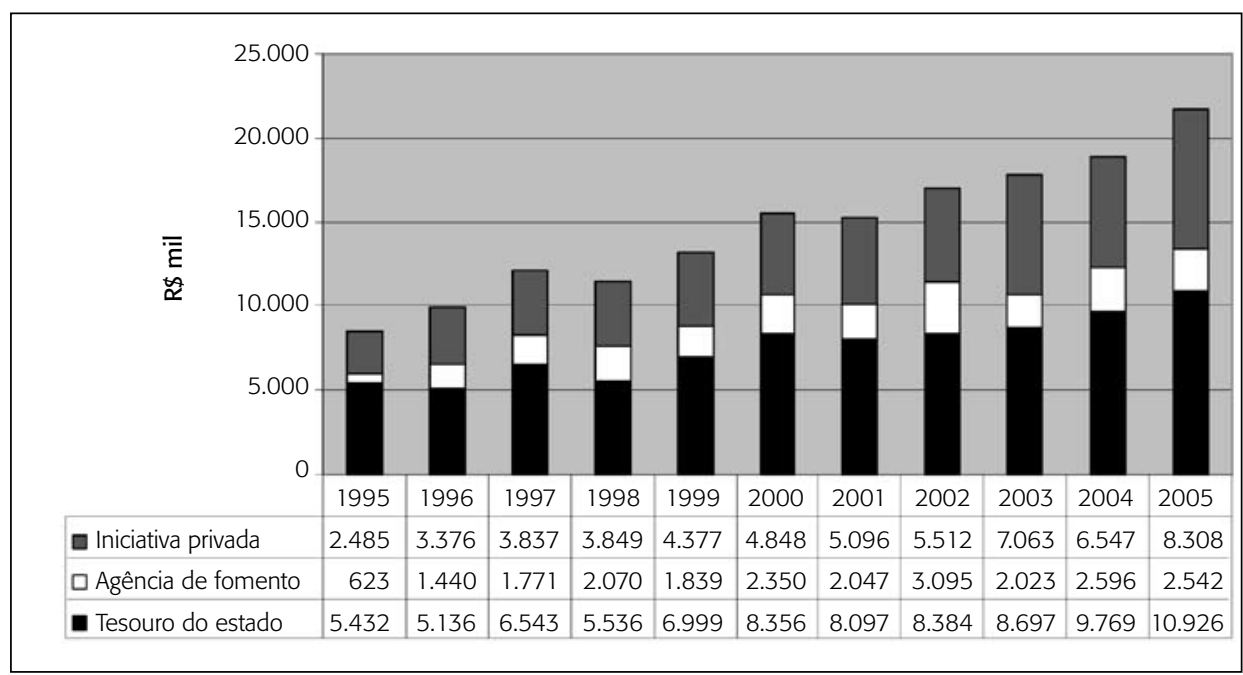

Fonte: Banco de dados do Ital.

Nesse processo de descentralização, cada UT voltou-se para as demandas de seu setor, criando uma competição entre as mesmas. Algumas unidades, em nome da eficiência, criaram seu próprio setor de eventos, boletins informativos, bibliotecas etc. Os centros tecnológicos investiram nos seus próprios laboratórios, com a justificativa de que os serviços eram muito específicos de cada setor, exigindo pessoal qualificado, de que só a unidade específica poderia dispor. 


\author{
Figura 5
} Ital - arrecadação das unidades técnicas junto à iniciativa privada e ao
fomento, em anos selecionados

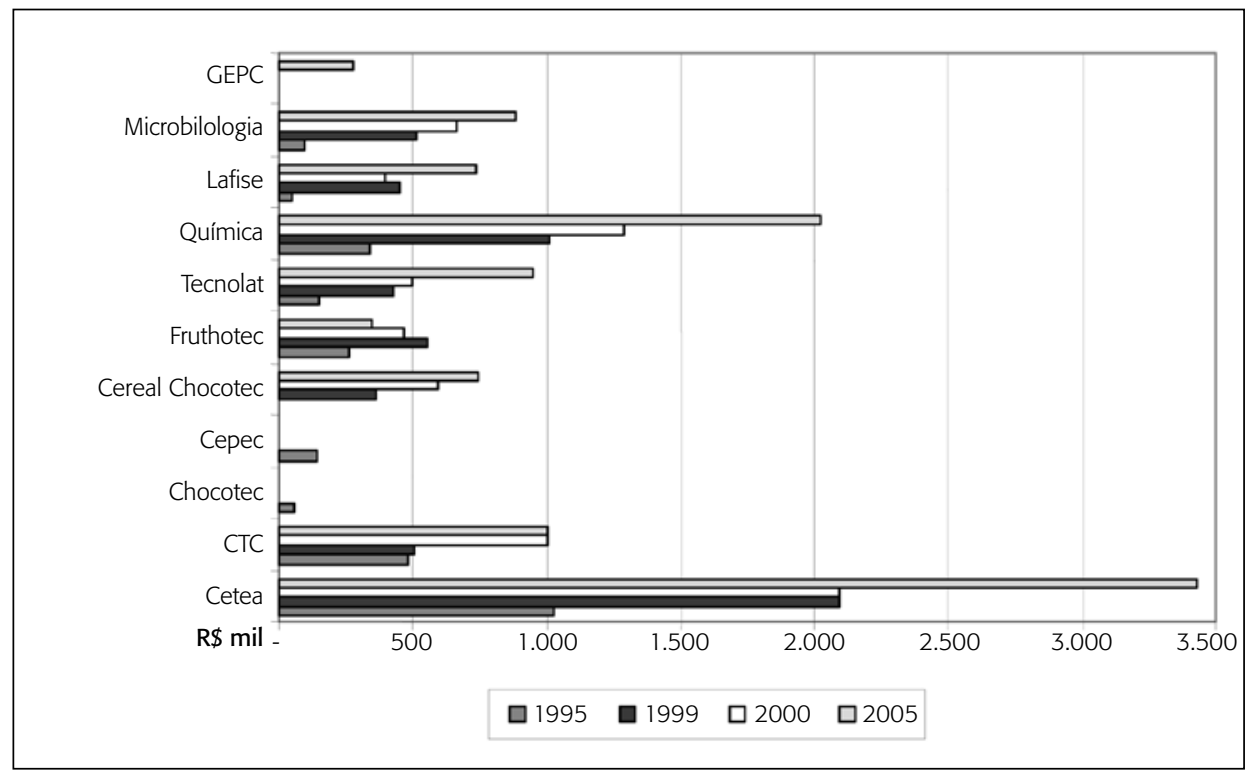

Fonte: Banco de dados do Ital.

As dificuldades encontradas para a expansão e entrada em novos mercados, aliadas à maior ou menor proatividade de cada UT e à capacidade administrativa de seus coordenadores, tiveram como reflexos a fusão do Cepec com o Chocotec, resultando no Cereal Chocotec, a emergência do GEE, depois GEPC, e o desmembramento da planta-piloto de pescado do CTC, localizada no Guarujá, com sua passagem para o Instituto de Pesca. Outro reflexo importante se observa no crescimento assimétrico das unidades técnicas, no que diz respeito à arrecadação extraorçamentária. A fusão do Chocotec, área criada em 1994, com o Cepec, área já bastante antiga no Ital, foi uma experiência difícil para ambos os centros, resultando, por algum tempo, num ritmo menor de crescimento para o Cereal Chocotec. ${ }^{15} \mathrm{O}$ Fruthotec ressentiu-se da saída de pesquisadores para o GEPC, em 2005, o que se refletiu na queda de sua receita extraorçamentária: de 1996 a 2004, sua arrecadação junto ao setor produtivo variou entre R\$ 199 mil e

\footnotetext{
${ }^{15}$ De 1996 a 1999, a arrecadação do Chocotec junto à iniciativa privada cresceu, em média, 58,3\% ao ano; após a fusão, a arrecadação Cereal Chocotec junto à iniciativa privada cresceu 24,9\%, em 2000; e 38,5\% em 2001. Neste último ano, a área de fomento sustentou o incremento da arrecadação extraorçamentária total.
} 
R\$ 348 mil; em 2005, caiu para R\$ 175 mil. Entre as unidades analíticas, somente a Química teve um crescimento significativo de arrecadação, no período, e entre os centros tecnológicos, apenas o Cetea (figura 5).

\section{PolítICAS E PRÁtICAS DE PLANEJAMENTO DAS ATIVIDADES-FIM}

As políticas de planejamento das atividades-fim estão consubstanciadas nas metas fixadas pelos indicadores estratégicos.

As metas eram, inicialmente, definidas pelas unidades, no final de cada ano. A Diretoria-Geral as consolidava e, no início do ano, eram aprovadas no CD como metas da instituição para aquele ano. As metas financeiras eram as mais importantes e, consequentemente, as mais cobradas das UTs. Com o decorrer dos anos, o processo de estabelecimento de metas foi se aperfeiçoando devido, principalmente, a uma inovação organizacional in business practices (OECD/European Communities, 2005:51), à implantação da ISO 9001:1994, em 1998; à sua recertificação pela ISO 9001:2000, em 2000; e seu processo de manutenção. ${ }^{16}$ No entanto, continuaram definidas pelas UTs, com posterior consolidação pela DG.

Paulatinamente, foram estabelecidos indicadores para as diferentes características dos produtos e processos ${ }^{17}$ da instituição, com o objetivo de acompanhar o desempenho da organização. Sua identificação, definição e sistematização foram se estabelecendo num processo de melhoria contínua, através de discussões na Comissão de Gestão da Qualidade (CGQ) e nas reuniões de CD. Esses indicadores são, geralmente, medidas numéricas de desempenho, relacionadas a uma ou a um conjunto de metas e, desde 2002, classificados em cinco modalidades: financeiros, de imagem, de produção, de competência e de organização/gestão. Em 2003, os indicadores de desempenho em vigor já eram 60. Anualmente, a alta direção ${ }^{18}$ seleciona alguns indicadores de desempenho que sejam estratégicos para a instituição e suas metas são estabelecidas em reunião do $\mathrm{CD}$ ou em reunião de análise crítica do sistema da qualidade. Os indicadores estratégicos em vigor, em 2005, e suas respectivas metas estão relacionados no quadro. Os demais indicadores não têm metas estabelecidas, mas sua medição auxilia em momentos de tomada de decisão.

\footnotetext{
${ }^{16}$ O Ital inovou ao implantar e manter a ISO 9001, pois foi um dos primeiros, se não o primeiro, IPPs no Brasil a implantá-la.

${ }^{17}$ Em 2005, os processos do Ital eram compostos por: 1) processos de gestão; 2) processos de realização do produto; e 3) processos de apoio ou suporte.

${ }^{18} \mathrm{O}$ termo alta direção surgiu com a ISO 9001 e se refere aos membros do Conselho Diretor.
} 
Quadro

Indicadores estratégicos e suas metas, em 2005

\begin{tabular}{|lllr|}
\hline & & Frequência & Meta \\
Indicador & Unidade & Mensal & 2005 \\
\hline Recursos obtidos do governo estadual & $\mathrm{R} \$$ mil/TNS* & 97,1 \\
Recursos obtidos de agências de fomento & $\mathrm{R} \$$ mil/TNS & Mensal & 28,1 \\
Recursos obtidos da iniciativa privada & $\mathrm{R} \$$ mil/TNS & Mensal & 65,4 \\
Recursos gastos com investimentos & $\mathrm{R} \$$ mil/TNS & Mensal & 13,6 \\
Recursos gastos com custeios & $\mathrm{R} \$$ mil/TNS & Mensal & 39,3 \\
Recursos gastos com pessoal & $\mathrm{R} \$$ mil/TNS & Mensal & 104,1 \\
Índice de satisfação de clientes externos & \% de satisfação & Anual & 91,6 \\
Índice de satisfação de clientes internos & \% de satisfação & Anual & 68,8 \\
Índice de avaliação de eventos & \% de satisfação & Por evento & 90,0 \\
Propostas de projetos aprovadas por agência de fomento & №/UT & Mensal & 3,0 \\
Eventos realizados & №/UT & Mensal & 4,3 \\
Artigos cientificos publicados em revistas indexadas & №/PqC & Mensal & 0,8 \\
Capacitação e treinamento dos recursos humanos & h/funcionário & Mensal & 17,3 \\
Resultado de auditorias internas & Pontos negativos/UT & Semestral & 87,0 \\
Projetos e eventos com outras unidades & № & Mensal & 39,0 \\
\hline
\end{tabular}

Fonte: Ital (2007).

* TNS = Técnico de nível superior (inclui todos os pesquisadores, da carreira de pesquisador científico ou não).

Com a descentralização e a simplificação da estrutura da instituição, criou-se um vazio no tratamento de problemas que atingem a indústria de alimentos como um todo e sua relação com outros setores, pois as UTs voltaramse para seus mercados específicos. Para preencher esse vazio, grupos especiais multidisciplinares foram criados, e alguns adquiriram caráter permanente: $\mathrm{o}$ de meio ambiente, o de apoio às exportações e o de segurança alimentar. A maior ou menor atuação de cada grupo especial dependia da proatividade de seu coordenador e do tempo que seus membros, quase sempre um representante de cada UT, podiam lhe dedicar.

O processo de estabelecimento de metas, priorizando a arrecadação junto à iniciativa privada, levou à ausência de metas institucionais de médio e longo prazos, estabelecidas em conjunto com os setores produtivo e governamental e articuladas com as tendências científicas e tecnológicas globais, com as mudanças no padrão de consumo no país e com os demais aspectos que possam afetar a indústria brasileira de alimentos.

A atividade-fim pesquisa científica e tecnológica não contratada pela iniciativa privada, ou seja, os projetos de P\&D institucionais, voltados às pes- 
quisas básica e aplicada e realizados com recursos de verba orçamentária ou de agências de fomento, eram considerados a atividade-fim, por excelência, do Ital, antes de sua reestruturação. Seu planejamento era, inicialmente, dentro de um grupo de programas prioritários, os quais incluíam um número variável de projetos, acompanhados pela Assistência Técnica de Programação (ATC), depois Comissão Técnico-Científica (Cotec), ligada diretamente à Diretoria-Geral.

Com a reestruturação, em 1995, a Cotec foi extinta e as pesquisas passaram a ser planejadas e acompanhadas dentro de cada unidade técnica; algumas estabeleceram suas próprias linhas de pesquisa e outras não as tinham. Assim, não havia programas ou linhas de pesquisa prioritárias da instituição.

De 2002 em diante, a pesquisa e desenvolvimento passou a ter como indicadores estratégicos os "artigos científicos publicados em revistas indexadas (№/PqC)", nacionais e internacionais, e as "propostas de projetos aprovadas por agência de fomento (№/UT)". A meta anual dos artigos científicos tem sido fixada, mas persistentemente não tem sido alcançada. ${ }^{19}$ Isso é negativo para um instituto de pesquisa; contudo, trata-se de um indicador difícil de ser interpretado isoladamente, já que a produção dos pesquisadores também se traduz em artigos em anais de eventos nacionais e internacionais, livros, capítulos de livros, artigos técnicos, manuais técnicos, teses, artigos de revisão e, ultimamente, em patentes. De 2000 a $2005,{ }^{20}$ caiu o número de artigos por $\mathrm{PqC}$ em periódicos nacionais indexados de 0,71 para 0,18 ; em periódicos internacionais indexados, caiu de 0,10 para 0,06 . De 2001 a 2005, o número de trabalhos por $\mathrm{PqC}$ em anais de eventos nacionais passou de 0,05 para 0,12 e o número de trabalhos por $\mathrm{PqC}$ em anais de eventos internacionais, de 0,03 para 0,68. Em outros tipos de publicação, a média no Ital, nesse mesmo período, foi de $0,04 / \mathrm{PqC}$ para livros publicados e o mesmo para capítulos de livros. Quanto às patentes, até 2005 elas não faziam parte dos indicadores de desempenho e o único dado oficial disponível é para 2004: número de patentes depositadas — seis ou 0,08/PqC; número de patentes obtidas - cinco ou 0,07/PqC.

Quanto aos projetos de pesquisa e desenvolvimento financiados por agências de fomento, o índice "total de propostas aprovadas/total de propos-

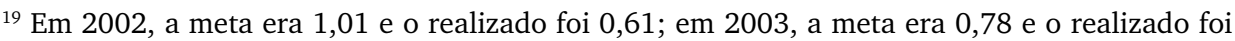
0,31 ; em 2004 , a meta era 0,97 e o realizado foi 0,61 ; e, em 2005 , a meta era 0,8 e o realizado foi 0,3 .

${ }^{20}$ Não há, no banco de dados do Ital, uma série completa sobre a produção dos pesquisadores em todos esses itens, para todo o período em estudo.
} 
tas enviadas às agências de fomento" é o indicador que melhor os traduz. ${ }^{21} \mathrm{O}$ índice passou de $60 \%$, em 2000, para 74,5\% em 2005, com pico em 2004, com $81,5 \%$ das propostas aprovadas.

Apesar da titulação $0^{22}$ ser de grande importância na busca por recursos de agências de fomento, dois importantes indicadores de desempenho medidos anualmente, a "qualificação dos funcionários das áreas-fim"23 e a "pontuação média dos PqC na carreira", não eram considerados estratégicos para a instituição, no período. Na prática, entretanto, algumas unidades técnicas incentivavam seus pesquisadores na busca por titulação para que pudessem concorrer por recursos de agências de fomento, pois eram importantes para obtenção de equipamentos de ponta, finalizações de plantas-piloto etc., ou seja, para ter recursos para investimento, pois de 1998 a 2005, a rubrica investimento, nos recursos do governo do estado de São Paulo (Gesp), apresentava o valor zero (banco de dados do Ital).

Quanto à atividade-fim "treinamento e formação de recursos humanos", os indicadores estratégicos são o número de eventos realizados por unidade técnica e o índice de avaliação por parte dos participantes dos eventos, pois eventos são formas de treinar e realizar a transferência de tecnologia. O Ital ainda acompanha os indicadores de desempenho "eventos por pesquisador", "número de estagiários por pesquisador" e "orientações por técnico de nível superior especialista (TNSE)". Quanto aos estagiários, o Ital manteve sua tradição. De 1989 a 1994 a média anual de estagiários que passaram pelas diferentes unidades do Ital foi de 231 estudantes, vindos de todas as partes do país, mas principalmente do estado de São Paulo; de 1995 a 2005, a média anual foi de 313. A média de estagiários por pesquisador passou de $2,9 \mathrm{em}$ 1995 para 3,4 em 2005, tendo chegado a 5,2 em 2001. No tocante à iniciação científica, desde 1993 o Ital é contemplado pelo CNPq com cotas de bolsas Pibic. No início do período em estudo, essa cota variava de 21 a 26 bolsas; em 2005, essa cota aumentou para 31 bolsas.

Em relação à atividade-fim "assistência tecnológica ao setor produtivo", são estabelecidas e acompanhadas as metas de arrecadação junto ao setor

\footnotetext{
${ }^{21}$ Esses dados passaram a ser coletados a partir de 2000 e se referem ao conjunto de propostas de projetos de pesquisa, projetos de infraestrutura e outros auxílios.

${ }^{22}$ Quanto à titulação, os pesquisadores do Ital se distribuíam, em 1995, em: $22 \%$ de doutores, $57 \%$ de mestres e $21 \%$ de graduados; em 2005 , em: $53 \%$ de doutores, $32 \%$ de mestres e $15 \%$ de graduados.

${ }^{23}$ Essa qualificação é definida por $(5 \mathrm{D}+4 \mathrm{M}+3 \mathrm{E}+2 \mathrm{G}+\mathrm{SG}) /$ total de funcionários das áreas-fim = pontos. Sua frequência de medição é anual. $\mathrm{D}=$ doutor, $\mathrm{M}=$ mestre, $\mathrm{E}=$ especialista, $\mathrm{G}=$ graduado, $\mathrm{SG}=$ segundo grau.
} 
produtivo nas categorias: projetos de $\mathrm{P} \& \mathrm{D}$, análises e ensaios laboratoriais, serviços tecnológicos e cursos e eventos. O processo de introdução de novos serviços para o setor em cada categoria foi contínuo, no período, resultando num portfólio bastante diversificado e aos poucos foi ocorrendo uma especialização dentro de cada UT, acentuando as diferenças entre elas.

A categoria que mais cresceu, tanto em oferta de novos serviços quanto em arrecadação, foi a de análises e ensaios laboratoriais. Inúmeras análises químicas, físicas e sensoriais, microbiológicas e de embalagens foram introduzidas durante o período e, à medida que as UTs responsáveis pelas análises laboratoriais ocuparam novos mercados e cresciam em arrecadação, elas modernizaram seus laboratórios, instalações e equipamentos, implantaram softwares avançados, habilitaram seus ensaios pela Anvisa e treinaram suas equipes. O número de análises e ensaios, realizados por ano, passou de 20.674, em 1995, a 70.944, em 2005, com ápice em 2002, quando alcançou o número de 86.745. Em todos os anos, a maior demanda foi pelas análises químicas. Em arrecadação, análises e ensaios passaram de R \$ 647 mil ou 26\% do total arrecadado pelo Ital junto à iniciativa privada, em 1995, a R $\$ 3.972$ mil ou 48\%, em 2005 (figura 6).

No final do período em estudo, os serviços tecnológicos se apresentavam como a segunda categoria em importância, tanto em arrecadação quanto em número e diversidade oferecida. Em 1995, em número de serviços realizados, era maior a participação dos serviços tecnológicos em relação aos projetos de P\&D, numa razão de 0,5:1,0, mas não em arrecadação; de 2002 em diante, os serviços tecnológicos passaram a ser, em número e em arrecadação, muito maiores: em 2005, o Ital arrecadou $\mathrm{R} \$ 813,2$ mil em 27 projetos e $\mathrm{R} \$ 1.444,3$ mil em 312 serviços tecnológicos (banco de dados do Ital, figura 6).

Cursos e eventos compõem a terceira categoria de serviços, em importância de arrecadação, que passou de R 492 mil, em 1995, a R $\$ 1.109$ mil, em 2005, um incremento de $125 \%$ (figura 6). Contudo, houve queda acentuada de sua posição relativa, pois, em 1995, representavam $20 \%$ da arrecadação junto à iniciativa privada, caindo para $13 \%$, em 2005. Isso se deveu mais à importância crescente das análises e ensaios e ao crescimento da demanda por serviços tecnológicos do que à capacidade inovativa do Ital em seus cursos e seminários: em 1995, as UTs ofereceram 22 eventos, tendo treinado 1.795 pessoas; em 2005, 47 eventos, treinando 2.472 pessoas. O número de eventos realizados por pesquisador passou de 0,20 em 1995 para 0,48 em 2005.

Os projetos de P\&D para a iniciativa privada compõem a quarta categoria em arrecadação: desenvolvimento de novos produtos e processos, 
aplicando tecnologias disponíveis e/ou inovadoras; aprimoramento de produtos e processos; adequação de produtos para exportação; estudos de vida de prateleira; engenharia de processo; estudos de desempenho de aditivos e novos ingredientes; anteprojetos industriais; e muitos outros. A arrecadação em projetos foi de R\$ 927 mil, em 2001, e R\$ 813 mil, em 2005 (figura 6).

Figura 6

Evolução da arrecadação pelas categorias de serviços oferecidos pelo Ital à iniciativa privada, 1995-2005

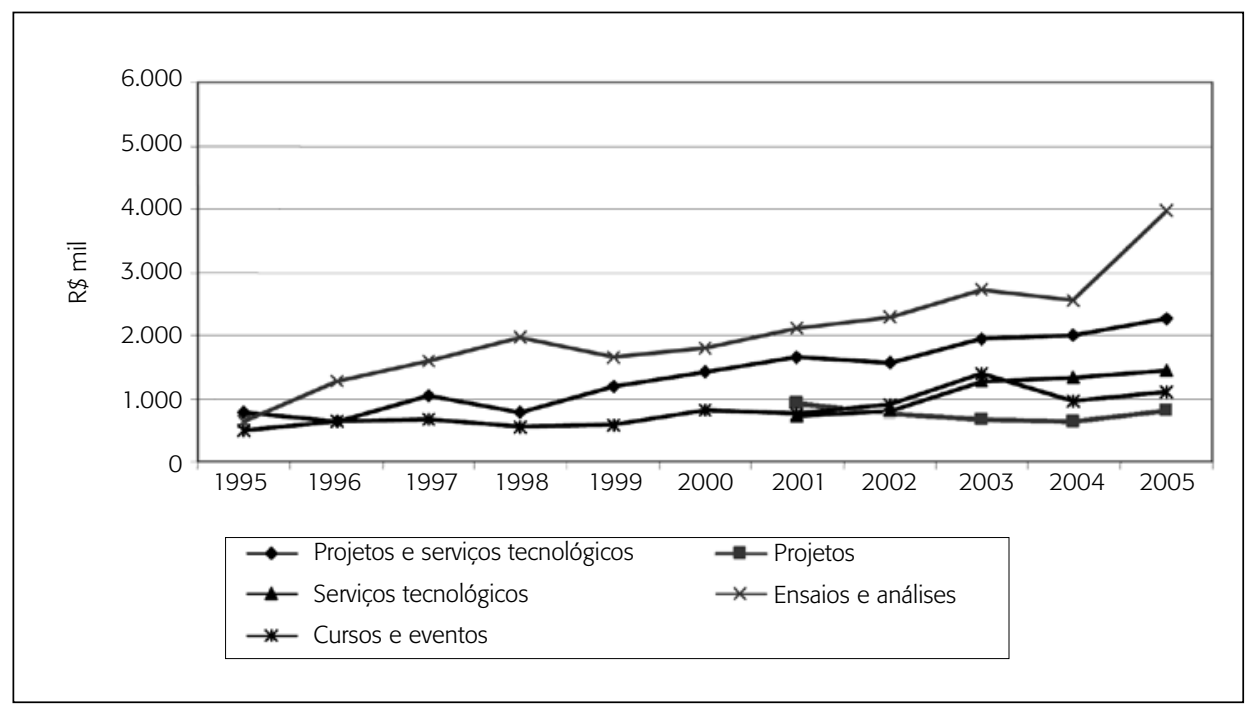

Fonte: Banco de dados do Ital.

Projetos de P\&D são trabalhos mais complexos do que os oferecidos pela categoria serviços tecnológicos, pois envolvem maior capacidade intelectual, tempo e equipes maiores. No caso de desenvolvimento ou aprimoramento de produtos, são necessárias análises críticas com o cliente para garantir que o que foi requerido é o que está em execução; no caso de transferência da tecnologia desenvolvida, exige-se a aplicação prática na empresa do cliente; e assim por diante. É preciso lembrar ainda que os projetos de P\&D exibem graus de exigências diferentes. Recente pesquisa realizada em duas unidades técnicas do Ital, Cereal Chocotec e Fruthotec mostrou que, de 80 projetos desenvolvidos entre 1995 e 2005 no primeiro centro, 58\% apresentaram grau muito elevado de exigência em estudo e aquisição de no- 
vos conhecimentos, ${ }^{24}$ enquanto, no segundo, de 77 projetos realizados entre 2000 e 2006, essa percentagem foi de 59\% (Garcia et al., 2007).

É também por meio dos projetos de P\&D para o setor produtivo que o Ital viabiliza a inovação nas empresas. Na mesma pesquisa citada foi observado que, no tocante ao desenvolvimento e aperfeiçoamento de produtos, 70\% dos projetos do Cereal Chocotec e $92 \%$ dos projetos do Fruthotec resultaram em produtos novos ou significativamente aperfeiçoados para a empresa ou para o mercado e, no tocante ao desenvolvimento ou aperfeiçoamento de processo, 36\% dos projetos do Cereal Chocotec e $86 \%$ dos projetos do Fruthotec apresentaram processos novos ou significativamente aperfeiçoados para a empresa ou para a indústria (Garcia et al., 2007).

Depreende-se pois, que a categoria projetos de P\&D para a iniciativa privada, apesar de aparecer em último lugar em arrecadação, é muito importante para o Ital, pois é através dela que a instituição realiza mais plenamente sua missão.

À medida que os anos passaram, as unidades técnicas foram se especializando em uma categoria de serviço para a iniciativa privada, o que se evidencia pela participação de cada uma na arrecadação da unidade, quando se considera o total das categorias, em 1996 e em 2005, à exceção do Cetea e do CTC, que apresentaram em 2005 uma participação mais equilibrada (tabela).

Tabela

Participação das categorias de serviços para a iniciativa privada, por unidade técnica, 1996 e 2005

\begin{tabular}{|lcccccc|}
\hline & \multicolumn{3}{c}{$\begin{array}{c}\text { Participação das categorias de serviços } \\
1996(\%)\end{array}$} & \multicolumn{3}{c|}{$\begin{array}{c}\text { Participação das categorias de serviços } \\
\text { 2005 (\%) }\end{array}$} \\
\cline { 2 - 7 } $\begin{array}{l}\text { Unidade } \\
\text { técnica }\end{array}$ & $\begin{array}{c}\text { Projeto e serviço } \\
\text { tecnológico }\end{array}$ & $\begin{array}{c}\text { Análise e } \\
\text { ensaio }\end{array}$ & Evento & $\begin{array}{c}\text { Projeto e serviço } \\
\text { tecnológico }\end{array}$ & $\begin{array}{c}\text { Análise e } \\
\text { ensaio }\end{array}$ & Evento \\
\hline Cetea & 9,9 & 68,9 & 21,3 & 39,2 & 42,4 & 18,4 \\
CTC & 17,2 & 54,8 & 28 & 36 & 31 & 33,1 \\
Chocotec & 67,6 & 3,8 & 28,6 & - & - & - \\
Cepec & 15,7 & 21,9 & 62,4 & - & - & - \\
\hline
\end{tabular}

\footnotetext{
${ }^{24} \mathrm{O}$ grau de exigência foi avaliado pelos pesquisadores líderes através de uma escala de Likert (Hayes, 1995), que ia de cinco (muitíssimo exigente em estudo e aquisição de novos conhecimentos) a um (nada exigente em estudo e aquisição de novos conhecimentos) (Garcia et al., 2007). Neste artigo, o termo grau "muito elevado" significa a soma das avaliações quatro (muito exigente) e cinco (muitíssimo exigente).
} 


\begin{tabular}{|lcccccc|}
\hline & \multicolumn{3}{c}{$\begin{array}{c}\text { Participação das categorias de serviços } \\
1996(\%)\end{array}$} & \multicolumn{4}{c|}{$\begin{array}{c}\text { Participação das categorias de serviços } \\
\text { 2005 (\%) }\end{array}$} \\
\cline { 2 - 7 } $\begin{array}{l}\text { Unidade } \\
\text { técnica }\end{array}$ & $\begin{array}{c}\text { Projeto e serviço } \\
\text { tecnológico }\end{array}$ & $\begin{array}{c}\text { Análise e } \\
\text { ensaio }\end{array}$ & Evento & $\begin{array}{c}\text { Projeto e serviço } \\
\text { tecnológico }\end{array}$ & $\begin{array}{c}\text { Análise e } \\
\text { ensaio }\end{array}$ & Evento \\
\hline Cereal & & - & - & 47,1 & 9,3 & 43,6 \\
Chocotec & - & - & 25,4 & 81,8 & 5,5 & 12,7 \\
Fruthotec & 49 & 25,5 & 25,4 & 75,3 & 24,7 & - \\
Tecnolat & 18,3 & 61,2 & 20,4 & 15,1 & 83,5 & 1,4 \\
Química & 45,2 & 42,9 & 11,9 & 16,5 & 81,3 & 2,1 \\
Lafise & 53,3 & 26 & 20,8 & 16,6 & 79,2 & 10,2 \\
Microbiologia & 16,6 & 51 & 32,4 & 10,6 & 4,9 & - \\
GEPC & - & - & - & 95,1 & 54,6 & 14,4 \\
Total Ital & 25 & 50 & 25 & 31 & & \\
\hline
\end{tabular}

Fonte dos dados primários: Banco de dados do Ital.

\section{PoLítICAS E PRÁTICAS dE AVALIAÇÃO INSTITUCIONAL}

Antes de 1995 não existiam mecanismos estabelecidos de avaliação institucional, em qualquer instância de poder, quer por parte da SAA, quer da CPA, quer da própria diretoria da instituição. ${ }^{25}$ Por parte de todas essas instâncias havia a necessidade de controle e fiscalização com fins regulatórios, de distribuição de verbas orçamentárias e de reposição de pessoal, entre outras funções que são papel do estado. Internamente, o que sempre houve no Ital foi uma inclinação da comunidade de pesquisadores em realizar a autoavaliação como mecanismo de luta por maiores verbas para pesquisa e maior autonomia de gerenciamento de seus recursos financeiros e humanos.

A partir de 1995, o processo de mudança detonado pela reestruturação e alimentado pelo primeiro planejamento estratégico, por causa da certificação ISO 9001 e pela acreditação de ensaios, entre outros, foi aos poucos introduzindo no Ital práticas de avaliação institucional, cujos resultados são utilizados para a sua melhoria contínua.

\footnotetext{
${ }^{25}$ Os institutos de pesquisa do estado de São Paulo e do Brasil, públicos ou particulares, até o término deste artigo, não dispunham de um sistema nacional de avaliação de suas atividades, como acontece com as instituições de ensino superior, cujo Sistema Nacional de Avaliação da Educação Superior (Sinaes) foi criado pela Lei no 10.861, de 14 de abril de 2004.
} 
No final do período analisado, o Ital dispunha de mecanismos internos e externos de avaliação institucional. Internamente, as pesquisas de clientes, externos e internos, as auditorias internas e as análises críticas do SGQ eram os principais mecanismos que geravam indicadores quantitativos, de transparente visibilidade para todos, e que alimentavam as análises qualitativas do Conselho Diretor e das UTs, orientando-os na tomada de decisão, adequação das políticas internas, redefinição das prioridades e realização de melhorias. Externamente, os mecanismos eram as auditorias de terceira parte do SGQ e as auditorias do Projeto Excelência na Pesquisa Tecnológica, da Abipti (Abipti, 2007).

As pesquisas anuais de satisfação e insatisfação dos clientes externos e internos são duas ferramentas de avaliação muito importantes. Ambas se iniciaram em 1996, com o Programa de Qualidade Total, mantiveram-se com a ISO e foram-se aperfeiçoando com o tempo. A pesquisa do cliente externo tem como objetivo avaliar o grau de satisfação e insatisfação dos usuários do Ital com os serviços realizados, identificar os aspectos considerados importantes no relacionamento deles com a instituição e colher sugestões de melhorias. Por sua vez, a pesquisa do cliente interno visa detectar pontos de melhoria nas diversas áreas e atividades do instituto, incluindo as unidades administrativas. Ambas as pesquisas têm caráter confidencial e os resultados são analisados com o auxílio de ferramentas estatísticas, dando origem a um relatório e às solicitações de ação corretiva (SAC) e solicitações de ação preventiva (SAP). Os resultados são divulgados por vários meios ${ }^{26}$ e analisados e discutidos dentro das unidades, que tomam as ações necessárias para as melhorias. Em 1996, primeiro ano da pesquisa, o índice de satisfação dos clientes externos foi de $72,6 \%$ e, em 2005 , foi de $89,4 \%$.

As auditorias internas do SGQ são realizadas duas vezes ao ano, por auditores internos devidamente treinados ${ }^{27}$ e reciclados. Abrangem praticamente todos os itens da NBR ISO 9001:2000 aplicáveis à unidade e, no caso dos laboratórios com ensaios acreditados, os elementos da NBR ISO/IEC 17025. As não conformidades encontradas e as possíveis melhorias são registradas nos formulários de SAC e SAP e seus posteriores desdobramentos são acompanhados e relatados em várias instâncias pelo RA.

\footnotetext{
${ }^{26}$ Os resultados das pesquisas de satisfação e insatisfação dos clientes, externos e internos, são divulgados nos painéis da qualidade, relatórios de atividade e relatórios de gestão, sendo que esses relatórios ficam à disposição da comunidade do Ital por meio do sistema Gedweb.

${ }^{27} \mathrm{Em} 2005$, eram 46 os auditores internos do SGQ do Ital.
} 
A análise crítica do sistema geral da qualidade é a avaliação formal feita pela direção de seu estado e da sua adequação à política da qualidade e seus objetivos. Participam o diretor-geral, o RA, os membros da CGQ, os diretores e vices das unidades técnicas e administrativas e os convidados. Engloba a análise dos resultados das auditorias internas e externas, relações com clientes, indicadores da qualidade, gestão de pessoas, entre outros. Os resultados ou as saídas da análise crítica são as recomendações de ações a serem tomadas para a melhoria da eficácia do sistema da qualidade, processos e produtos, em relação aos requisitos dos clientes. Com o tempo, foram se aprofundando os compromissos dos dirigentes e dos funcionários com os objetivos da qualidade, e as reuniões de análise crítica passaram a ter um papel fundamental no processo de autoavaliação e melhoria contínua da instituição.

Quanto à avaliação externa, as auditorias de terceira parte têm tido um papel fundamental para o Ital, pois contribuem positivamente para a manutenção de um sistema de gestão da qualidade de padrão internacional e chancelado por empresas ou entidades certificadoras externas, idôneas ${ }^{28}$ e independentes.

O Projeto Excelência na Pesquisa Tecnológica, desenvolvido pela Abipti (Associação Brasileira dos Institutos de Pesquisa Tecnológica), em parceria com o MCT (Ministério de Ciência e Tecnologia) e a Finep, teve a participação do Ital desde o início, em maio de 1998. O objetivo primordial do projeto é promover a melhoria do desempenho dos institutos de pesquisa tecnológica através da busca da excelência em sua gestão. $O$ modelo de referência é o Plano Nacional da Qualidade (PNQ). A importância do projeto está na comparação das instituições, por meio de um conjunto de indicadores de desempenho adequados às suas atividades, e na troca de informações sobre as boas práticas de gestão. As auditorias de terceira parte são feitas entre os institutos participantes do projeto que aderiram ao ciclo de avaliação e, para isso, elaboraram o relatório de gestão. A pontuação máxima é de mil pontos (Abipti, 2007). O Ital foi avaliado em quase todos os ciclos do projeto, ${ }^{29}$ tendo sempre alcançado pontuação acima da média geral. ${ }^{30}$ Contudo, seus avanços na direção da

\footnotetext{
${ }^{28}$ As auditorias de certificação, recertificação e manutenção foram feitas, no período estudado, pelas empresas Associação Alemã para Certificação de Sistemas de Gestão — DQS do Brasil e Fundação Carlos Alberto Vanzolini.

${ }^{29}$ De 1998 a 2005, houve sete ciclos de avaliação, tendo sido avaliadas de 13 a 16 entidades em cada um.

${ }^{30}$ Ciclo 2001: média Ital $=267$ e média geral $=209,9 ;$ ciclo 2002: média Ital $=285$ e média geral $=278$; ciclo 2004: média Ital $=260$ e média geral $=232,2$. Nos ciclos 2003 e 2005, o Ital não participou (dados obtidos junto ao sistema de gestão da qualidade).
} 
excelência de sua gestão, de acordo com o PNQ, têm sido pequenos e uma das razões pode ser a não incorporação efetiva dos valores e requisitos desse modelo de referência. O modelo do Ital tem sido, de fato, a ISO 9001 e 17025.

\section{Considerações finais}

Com a evolução de seus modelos institucional e, principalmente, gerencial, o Ital se tornou uma instituição bastante complexa, podendo ser classificada como uma organização híbrida, pois nela coexistem uma estrutura burocrática, cujo funcionamento é regido pelos padrões da administração direta do estado, e uma estrutura descentralizada de centros de negócios, que devem justificar sua existência por meio de sua capacidade de autossustentação, ou seja, é um instituto público de pesquisa, gerido como se fosse uma empresa.

O modo como se reestruturou, em 1995, pode ser definido como uma mudança organizacional radical, seguida de mudanças organizacionais incrementais, que resultaram numa trajetória institucional que o aproximou efetivamente do setor produtivo e aumentou a participação das fontes extraorçamentárias no seu orçamento global, objetivos primordiais de sua reestruturação. A liberdade de gestão, permitida pelo componente estratégico do modelo gerencial, foi muito bem aproveitada, possibilitando-lhe estratégias bem-sucedidas para a consecução de seus objetivos. Benefícios típicos da execução bem-sucedida de suas estratégias e novas formas de relacionamento com o setor produtivo são: o aumento da satisfação de seus clientes externos, a diversificação e o incremento dos tipos de serviços oferecidos ao setor produtivo e o incremento dos recursos advindos da iniciativa privada.

A organização interna descentralizada do Ital estava contida na reestruturação, mas não estava pronta, não só porque não incluiu a área administrativa, como o próprio modo de gestão das unidades técnicas não estava claro. Sua trajetória foi evolutiva, tendo como elemento central o aprendizado organizacional. Os desafios das reestruturações posteriores a 1995 transformados em oportunidades, a cultura da melhoria contínua, as diversas ferramentas de gestão fornecidas pelas ISO 9000 e 17025 e a entrada das UTs em novos mercados são claras demonstrações de que o Ital é uma instituição que aprende e evolui.

Antes da reestruturação, o Ital já era uma instituição de referência no país, pelas pesquisas que desenvolvia e pelo impacto delas na indústria alimentícia. Após a reestruturação, essa situação se consolidou devido, principalmente, ao seu papel de promotor da inovação tecnológica nas empresas e à 
assistência tecnológica às mesmas. No entanto, entre suas três atividades-fim, $\mathrm{P} \& \mathrm{D}$, assistência tecnológica e treinamento, o modelo organizacional adotado priorizou os dois últimos, e a $\mathrm{P} \& \mathrm{D}$, atividade-fim por excelência do Ital em seus primórdios, passou para terceiro plano.

Enquanto existem planos de ação para melhoria dos laboratórios e acreditação de ensaios e análises, melhorias e instalações de novas plantas-piloto e equipamentos, oferta de novos ou melhorados treinamentos etc., visando atender melhor o usuário da iniciativa privada, a P\&D institucional continuou a ser tratada como era no início da reestruturação, ou seja, sem visão de longo prazo e articulação com o desenvolvimento científico e tecnológico globais. A situação da P\&D institucional no Ital pode ser uma forte razão para a instituição não ter deslanchado na arrecadação junto às fontes de fomento, o que coloca a importância de se conhecer o perfil das pesquisas institucionais desenvolvidas pelos pesquisadores do Ital.

Como a ênfase é para a arrecadação junto ao setor produtivo, as unidades atendem, fundamentalmente, as demandas espontâneas, resultando em ausência de metas de médio e longo prazos, estabelecidas em conjunto com os setores produtivo e governamental e articuladas com as tendências globais, o que reforça a constatação de falta de visão de longo prazo.

Se, por um lado, pode-se dizer que a instituição tem respondido bem aos desafios do mercado, por outro, a falta de uma visão global e de longo prazo das tendências científicas e tecnológicas e a pequena ênfase na P\&D institucional podem gerar rigidez na geração e oferta de conhecimento para estar à frente da demanda, interferindo, assim, no potencial inovador do Ital, pois a performance competitiva de longo prazo de qualquer IPP reside na sua capacidade de contínuo aprendizado científico e tecnológico e no avanço do conhecimento.

A política de trabalhar por demanda foi, com o tempo, acentuando as diferenças entre as unidades técnicas, que passaram a se especializar em tipos de serviços oferecidos. A descentralização proporcionou ao Ital um melhor atendimento das demandas das empresas, nos diferentes ramos alimentícios, um aumento da capacidade de lidar com os diferentes graus de complexidade dos problemas colocados pelo setor produtivo e o aumento da capacidade de mobilizar o conhecimento para a solução de problemas. Contudo, a descentralização foi levada ao extremo, acirrando a competição entre suas unidades, criando políticas de recursos humanos muito diferenciadas e capacidade de gestão e inovação organizacional também diferenciadas, aumentando a distância entre elas no que concerne à arrecadação extraorçamentária. 
A complexidade da divisão do trabalho não foi considerada na reestruturação. Objetivava-se uma estrutura enxuta, mas aos poucos a divisão do trabalho foi se impondo, criando várias estruturas ligadas à Diretoria-Geral e uma tendência de departamentalização nas unidades, com a criação de gerências, setor de eventos, entre outros. Nesse processo, várias necessidades da instituição não foram atendidas, como a proteção da propriedade intelectual.

As políticas e práticas de avaliação institucional do Ital têm levado a uma série de pequenas mudanças, reforçando valores como melhoria contínua, educação continuada, trabalho em equipe, qualidade no fazer, que, no seu cômputo final, têm resultado numa instituição mais fortalecida, que se firma pela competência de seus pesquisadores, qualidade dos seus serviços e compromisso com o setor produtivo e com a sociedade. No entanto, falta na avaliação institucional maior ênfase à avaliação da P, D\&I do Ital, atividade-fim que aparece em primeiro lugar em sua missão, mas em último no dia a dia.

Finalmente, o Ital não precisou sair da administração direta do estado para realizar as inúmeras inovações organizacionais e aumentar os recursos conseguidos junto à iniciativa privada. A flexibilidade e a autonomia alcançadas resultaram das decisões gerenciais estratégicas tomadas e implementadas. Contudo, o Ital não conseguiu diminuir sua dependência dos recursos governamentais, uma vez que os recursos de fomento somados aos orçamentários perfaziam $62 \%$ de seu orçamento total, 10 anos depois da reestruturação.

Conclui-se, portanto, que a reorganização do Ital em unidades técnicas descentralizadas trouxe-lhe vantagens inegáveis. Sua trajetória institucional aprofundou os laços com o setor produtivo e aumentou a participação das fontes extraorçamentárias no seu orçamento total. O componente estratégico de seu modelo gerencial teve um papel muito importante nesse desenvolvimento. No entanto, seu modelo organizacional começa a apresentar sinais de esgotamento, entre eles a persistente disparidade entre as unidades tecnológicas, analíticas e de embalagem quanto à arrecadação junto à iniciativa privada e ao fomento, as diferenças de gestão entre elas, a pequena ênfase na P\&D institucional, que acaba reforçando a política de trabalhar por demanda, entre outros aspectos, colocando desafios para a sua continuidade como instituição de referência.

\section{Referências}

ASSOCIAÇÃO BRASILEIRA DAS INSTITUIÇÕES DE PESQUISA TECNOLÓGICA. Projeto Excelência na Pesquisa Tecnológica. Disponível em: <www.abipti.org.br/Excelencia/Introducao.htm>. Acesso em: 16 mar. 2007. 
GARCIA, Ana Elisa Brito; SALLES-FILHO, Sergio. Reorganização da pesquisa e internalização da lógica de mercado na ciência e tecnologia de alimentos: o caso do Ital. In: SEMINÁRIO LATINO-IBEROAMERICANO DE GESTÃO TECNOLÓGICA — ALTEC 2005: Innovación Tecnológica, Cooperación y Desarrollo, 11., Salvador, 2005. Anais eletrônicos... Salvador: Tec Art, 2005. 1 CD-Rom.

; ANDRADE, Talita Pires de Camargo; GERMER, Silvia. O papel do ITAL como agente do processo de inovação e de desenvolvimento tecnológico visto através do impacto dos projetos de $P \& D$ na iniciativa privada: relatório Pibic final 2006/2007. Campinas: Ital, 2007. 102 p.

GOODE, W. J.; HATT, P. K. Métodos em pesquisa social. Tradução de Carolina Martuscelli Bori. São Paulo: Companhia Editora Nacional, 1960. 494 p.

INSTITUTO DE TECNOLOGIA DE ALIMENTOS. Relatório de gestão 2005: Projeto Excelência na Pesquisa Tecnológica, Abipti - Ciclo 2006. Campinas: Ital, 2006. Disponível em: <www.gedweb.com.br/ital/> . Acesso em: 21 fev. 2007.

KIM Linsu; NELSON, Richard R. (Orgs.). Tecnologia, aprendizado e inovação: as experiências das economias de industrialização recente. Tradução de Carlos D. Szlak. Campinas: Unicamp, 2005. 503 p.

ORGANIZATION FOR ECONOMIC CO-OPERATION AND DEVELOPMENT. Manual de Frascati 2002: medición de las actividades científicas y tecnológicas. Propuesta de norma práctica para encuestas de investigación y desarrollo experimental. Madrid: Fecyt, 2003. 282 p.

; STATISTICAL OFFICE OF THE EUROPEAN COMMUNITIES. Oslo manual: guidelines for collecting and interpreting innovation data. 3. ed. Paris: OECD, 2005. $164 \mathrm{p}$.

SALLES-FILHO, Sergio (Coord.). Ciência, tecnologia e inovação: a reorganização da pesquisa pública no Brasil. Campinas: Komedi, 2000. 413 p.

et al. Institutional trajectories of public research institutes: a proposal of theoretical interpretation. In: TRIPLE HELIX INTERNATIONAL CONFERENCE, 3., 2000, Rio de Janeiro. The endless transitions. Rio de Janeiro: UFRJ/Coppe, 2000. 1 CD-Rom.

; BONACELLI, Maria Beatriz; MELLO, Débora. Metodologia para o estudo da reorganização institucional da pesquisa pública. Parcerias Estratégicas, n. 9, p. 86-108, out. 2000. Disponível em: <www.mct.gov.br/CEE/revista/Parcerias9/ 10revista9Metodologia.pdf $>$. Acesso em: 28 mar. 2005.

SOUZA, Willy Hoppe de; SBRAGIA, Roberto. Institutos tecnológicos industriais no Brasil: desafios e oportunidades contemporâneas. Brasília: Abipti, 2002. 263 p. 
TEIXEIRA, Cyro Gonçalves; TISSELLI, Luiza Helena P. Camargo. Ciência e tecnologia de alimentos na Secretaria de Agricultura e Abastecimento do Estado de São Paulo. Campinas: Ital, 1991. 181 p.

TOLEZANO, José Eduardo et al. Carreira do pesquisador científico dos institutos públicos de pesquisa do estado de São Paulo - alavanca para inserção social e para o desenvolvimento econômico: o sistema de avaliação continuada do desempenho técnico-científico, uma experiência de 30 anos. In: CONGRESSO ABIPTI 2006 - Competitividade e riqueza nacional: o futuro das instituições de pesquisa no Sistema Nacional de Ciência, Tecnologia e Inovação, 2006, Campinas. Anais eletrônicos... Campinas: Jtec, 2006. 1 CD-Rom. 